\title{
O direito à saúde na visão de um conselho municipal de saúde
}

\author{
The right to health from the point of view of \\ members of a local health council
}

Sueli Gandolfi Dallari 1

Rubens de Camargo Ferreira Adorno 1

Mara de Mello Faria 1

Nur Shuqaira Mahmud Said Abdel Qader Shuqair 1

Solange Trewikowski 1

\footnotetext{
1 Faculdade de Saúde Pública, Universidade de São Paulo. Av. Dr. Arnaldo 715, São Paulo, SP 01246-904, Brasil.
}

Abstract Based on a qualitative methodology using interactive techniques (in-depth open interviews), this study discusses both the concept of the right to health and potential ways to claim this right from the point of view of a group of full members of the Local Health Council in the City of São Paulo during the 1993-1996 term. The study al so interprets a number of issues related to "health advocacy", a potential locus of support and advice for groups working to improve health conditions for the population.

Key words Health Rigths; Civil Rights; Health Planning Technical Assistance; Health Policy

Resumo A partir de metodologia qualitativa, utilizando-se de técnica interativa (entrevista aberta, em profundidade), o presente estudo discute o concei to de direi to à saúde, bem como as formas possíveis de rei vindicá-lo, através da óti ca de al guns dos membros efeti vos do Consel ho Municipal de Saúde do Município de São Paulo, gestão 1993-1996. Estetrabal ho permitiu também interpretar questões relaci onadas à "advocacia em saúde", que vem a se constituir, num futuro, numa instância de apoi o e assessoria a grupos que trabalham pela mel horia da saúde coletiva da população.

Palavras-chave Direito à Saúde; Direitos Civis; Assistência Técnica ao Planejamento em Saúde; Política de Saúde 


\section{Introdução}

A Constituição de 1988 abre perspectivas para apoiar ações no domínio social, ou ações na esfera pública que possam remeter à "questão social", tanto por dar tratamento privilegiado aos direitos sociais que ela inscreve, quanto por oferecer instrumentos que possibilitam ao cidadão concretizar as exigências de um Estado de Justiça Social, fundado na dignidade da pessoa humana.

A organização social desenhada nessa constituição prevê a participação do povo na gestão pública, seja ou não por via institucional. É a prevalência da vontade do povo (entendido como instância jurídica e reconhecido como instância de poder) sobre aquela de qualquer indivíduo ou grupo, pois democracia implica autogoverno e exige que os próprios governados decidam sobre as diretrizes políticas fundamentais do Estado.

Pensando nessa forma de organização, o legislador previu canais institucionais de participação. Na Constituição Federal, encontramos referência no Capítulo da Seguridade Social, art. 198. Este assunto foi regulamentado através da Lei no 8.142, de 28 de dezembro de 1990, que dispõe sobre a participação da comunidade na gestão do Sistema Ú nico de Saúde - SUS (artigo 10). Essa participação se dá através dos Conselhos de Saúde, que são instâncias de ação política que articulam, no interior do campo da saúde, as ações do Estado e da cidadania, com a finalidade de ampliar o controle social na gestão do Sistema Único de Saúde SUS. Os Conselhos de Saúde não são os únicos órgãos controladores das ações do SUS, uma vez que os tradicionais instrumentos de controle da gestão pública existentes nas diferentes esferas dos poderes legislativo e judiciário permanecem ainda aplicáveis.

Conforme o disposto nessa lei, nos ConseIhos de Saúde a representação dos usuários deve ser paritária em relação ao conjunto dos demais segmentos. Isso garante aos usuários $50 \%$ dos representantes (art.1o, parágrafo 4o). Tais consel hos têm caráter deliberativo, competindo ao chefe do poder legalmente constituído, em cada esfera do governo, homologar as decisões tomadas (art.1o, parágrafo 2o). Decisões que tratam da formulação de estratégias e do controle da execução da política de saúde, incluindo os aspectos econômicos e financei ros.

Os municípios, segundo a Constituição Federal (arts. 23, II. c/ c 30,VII) e a Lei Orgânica da Saúde (Lei no 8.080, de 19 de setembro de 1990), terão a responsabilidade de cuidar da saúde de seus munícipes, cabendo ao Estado e à União a cooperação financeira e técnica, quando preciso, na implantação e organização das tarefas necessárias a tal projeto. A legislação municipal deve ajustar-se aos princípios de organização do Sistema Ú nico de Saúde SUS na Lei Orgânica do Município, nas demais leis municipais relacionadas à saúde e, especialmente, na lei do Plano Municipal de Saúde.

Na Lei Orgânica do Município de São Paulo, no Capítulo da Saúde, encontramos disposições sobre formas de organização da participação popular na gestão dos serviços, destacando-se a obrigação de realizar a Conferência Anual de Saúde e audiências públicas periódicas, como mecanismos de controle social de sua gestão (art. 217). Encontramos, também, referência à criação do Conselho Municipal de Saúde, órgão normativo e deliberativo, com estrutura colegiada, composto por representantes do Poder Público, trabalhadores da saúde e usuários, o qual, além de outras atribuições, deverá promover os mecanismos necessários à implementação da política de saúde nas unidades prestadoras de serviço (art. 218). Há, portanto, a institucionalização da participação popular, que controla a gestão do Sistema Único de Saúde no Município de São Paulo.

Realizamos uma pesquisa junto aos membros efetivos do Conselho Municipal de Saúde da cidade de São Paulo (CMS/ SP) - gestão 1993 - 1996 - com o objetivo de conhecer como esses agentes explicam e concebem o direito à saúde. Esse trabalho foi realizado durante o período de outubro/ novembro de 1994 e permitiu também estudar as formas de instrumentalizar os membros do Conselho, em mecanismos de reivindicação do direito, bem como obter subsídios para a implantação de Escritórios de "Advocacia em Saúde".

O CMS/SP enfrentava dificuldades, nessa ocasião, com relação a conflito referente à discussão e implantação do plano de terceirização dos serviços de saúde na região do Campo Limpo, que se originou na proposta de convênio a ser firmado entre a Prefeitura de São Paulo e a Associação Paulista de Medicina, relativa ao gerenciamento do Hospital Municipal de Campo Limpo, refletindo nas entrevistas realizadas.

Em termos de sua composição, dos 61 membros do Consel ho (efetivos e suplentes), cerca de $1 / 3$ (32\%) pertencia aos "M ovimentos de Saúde" das distintas regiões do Município de São Paulo, fazendo parte, portanto, das organizações existentes nos bairros, e ficaram sendo conhecidos também como representantes de "Movimentos Sociais"; nessa linha de tradição dos atores de "movimentos populares", encontravam-se, da mesma forma, os re- 
presentantes de Sindicatos e de Centrais Sindicais (como a Central Ú nica dos Trabalhadores), representando cerca de $10 \%$ dos membros. A administração pública, em seus diversos segmentos, possuía cerca de $22 \%$ dos representantes, $15 \%$ pertenciam a entidades de representação de empresas privadas, e o restante constituía-se de representantes de associações de doentes, entidades filantrópicas, consel hos e associações profissionais e de universidades.

Tendo em vista que parte dos membros do CMS/SP são representantes de movimentos sociais, houvemos por bem buscar na literatura científica subsídios que permitiram o entendimento desse processo na análise dos resultados dessa investigação.

Democracia, cidadania e movimentos populares

No Brasil, a questão da "participação" na área da saúde colocou-se em pauta a partir de finais da década de 70, quando tanto as crises econômico-políticas no cenário nacional e internacional intensificaram os problemas sociais, quanto a organização da população no âmbito do "bairro", reivindicando melhoria da infraestrutura e maior disponibilidade de bens de consumo coletivos, teve início. Essa "participação", denominada "movimento" (de bairro, de mães, de moradores etc.), acabou por se traduzir ao longo da década, pela conjunção com a ação de outros atores sociais presentes nos serviços, na burocracia do Estado, nas universidades e participando de outros "movimentos" no setor saúde, no tema: "saúde - um direito de todos e dever de Estado".

A referência a "movimento" constituía uma rejeição herdada, desde os anos 60 , ao uso do conceito "participação", que teria assumido frente a esses atores políticos um significado "ideológico": a mera alusão a esse termo fazia transparecer a idéia de controle, cooptação por parte do "poder", do "Estado". Essa referência expressava uma atitude de rejeição às instituições, a qual havia presidido a "cultura política" das esquerdas em meio aos anos 60 e que se intensificara em países da América Latina devido à existência de regimes autoritários, assumidos abertamente ou tutelados pelas forças militares.

O termo "movimento" remetia, por sua vez, ao conceito de "movimentos sociais", presente na sociologia e nas ciências políticas de maneira mais incisiva a partir da década de 70. Retomava-se a discussão em torno do que seria uma teoria contemporânea sobre os "movimentos sociais" a partir de duas tradições de interpretação da sociedade: como construção histórica e campo de conflitos (Adorno,1992a). Essas interpretações também incorporariam a discussão a respeito da "democracia" e seu sentido contemporâneo, por referência a autores como Bobbio, Arendt, Habermas, que valorizam a existência dos movimentos sociais, atuando na sociedade, sem excluir a democracia representativa. Do ponto de vista sociológico, esse conceito seria tratado de forma mais elaborada e intensa na obra do sociólogo francês Alain Touraine (Touraine, 1989), que analisa inclusive a situação dos movimentos e dos atores sociais na América Latina.

No Brasil, na década de 70, os movimentos sociais expressavam tanto a idéia de oposição institucional, como de extensão de direitos. Já na década de 80, o movimento social e a participação são interpretados como inovadores da cena política a partir de trabal hos publicados na área da Saúde Coletiva e das Ciências Sociais, seja como formas de pressionar o Estado a realizar suas tarefas no campo social (Valla \& Siqueira, 1989), expressando novas identidades sociais e políticas que se oporiam à política e às interpretações tradicionais da sociedade, em busca de autonomia (Sader, 1988); seja como resultado do trabalho de "articuladores sociais", que se relacionam com técnicos na burocracia pública (Jacobi, 1989), ou ainda como parte de um movimento social de caráter mais amplo e genérico, que logrou inscrever sua participação no plano político e institucional da sociedade com a chamada "transição democrática" da sociedade brasileira (Adorno, 1992b). No sentido da extensão dos direitos e enquanto participantes da política social do Estado, os movimentos sociais são interpretados como interlocutores que passam a ser reconhecidos pela burocracia estatal (Jacobi, 1989), levando, igualmente, à formação de novas identidades que incorporariam aspectos da sociabilidade local à esfera pública (Sader, 1988).

As demandas populares ou sociais por infra-estrutura e por serviços de saúde, incluindo-se aí o acesso aos serviços, acabam "politizando" os atores sociais, levando-os à conquista de direitos e ao desenvolvimento de ações relacionadas à cidadania. Sader (1988) fala dos articuladores sociais que transformam as demandas e tentam organizar a forma de reivindicação, dando origem, na saúde, ao termo cidadania, que aparece como direito social. Durante a "transi ção democrática" no Brasil, a discussão dos direitos passou pela superposição entre demandas sociais e movimentos sociais pela construção da democracia. A exclusão dos direitos sociais é atribuída à falta de direitos políticos. A existência de grandes níveis de de- 
sigualdade, convivendo com padrões de consumo e de valores da "modernidade", fez com que a experiência da sociedade brasileira se diferenciasse da descrita pelos teóricos do Direito, que concebem uma evolução cronológica do alcance dos direitos de primeira geração (políticos e civis) e os de segunda geração (direitos sociais). Aqui ocorre uma superposição ou uma assimilação; os atores sociais a que nos referimos, quando expressam o significado de "cidadania", o fazem identificando o espaço "político" como cenário para conquistas "econômicas" e "sociais", questionando a falta de direitos sociais: a precariedade de serviços, a discriminação a que é rel egado o "serviço público", como serviço de pobre, que seria outra "categoria de cidadão". Portanto, ressaltamos que um dos aspectos mais relevantes desses "movimentos sociais" foi, e tem sido, à medida em que essas referências encontram-se presentes, inclusive nos discursos que coletamos junto aos representantes do Conselho Municipal de Saúde, o de "cristalizar" o significado de cidadania, não somente em termos de conquistas materiais e sociais, mas também na constituição de uma “identidade" que se opõe à idéia da exclusão, ou de uma sociedade com dois tipos de "cidadãos". O termo cidadania deixa de ter seu significado meramente "jurídico", para indicar esse "emblema" do "Movimento Social".

Contemporaneamente, os "movimentos sociais" atingem um nível de identidade e ação mais rigoroso a partir do momento em que expressam seu conflito em relação à "orientação de gestão da sociedade", ou seja, num campo em que se dá a oposição em torno da imagem de sociedade que os atores sociais visam a criar (Touraine, 1984). Essa visão, construída no domínio da sociologia, identifica-se com posturas teóricas como as de Bobbio et al. (1992) no campo do direito e da ciência política. A construção de novos direitos é possível através de uma nova forma de interpretar e pensar, gerando nova orientação para a sociedade, a partir de seus grupos mobilizados ou envolvidos em defesa de uma causa.

O que podemos verificar hoje é que está havendo uma redefinição das práticas entre Estado e população. O Estado começa a internalizar elementos que faziam parte das reivindicações dos movimentos sociais, como o ConseIho Popular de Saúde, que é reconvertido dentro de um formato institucional para Conselho Gestor, criando condições para a inserção dos usuários dos movimentos organizados nesse processo de vigilância, de controle, de acompanhamento de gestão.
A pesquisa de campo realizada entrevistou atores sociais de vários segmentos, desde aqueles que transitavam pelas ruas do "bairro", apontando demandas e questões, aos representantes de associações de bairro e, por fim, os representantes do Conselho Municipal de Saúde. Este artigo apresenta e discute os discursos desses últimos atores.

\section{Metodologia}

O trabalho de campo mais amplo em que se inscreve a dimensão tratada neste artigo foi realizado em torno do problema das imagens e demandas sobre a cidade, o bairro e a saúde, a questão da representatividade e do conceito de "advocacia em saúde". Foi constituído com base em um desenho metodológico que, empregando as chamadas "técnicas qualitativas de pesquisa social", buscou apreender a construção do conceito de saúde e das formas de conquistá-la na esfera pública.

Como tal, no trabalho mais amplo, estabeleceram-se três planos de desenvolvimento da pesquisa de campo: o primeiro, constituído por um espaço geográfico determinado dentro de uma área urbana, em que se utilizou a contribuição do método etnográfico para conhecer o cenário sócio-demográfico dessa região; juntamente, foram realizadas entrevistas baseadas em roteiros semi-estruturados com representantes locais e representantes do ConseIho Municipal de Saúde. Também realizamos entrevistas com técni cos e administradores de instituições locais, nas áreas de saúde, segurança pública, administração municipal e lazer, buscando identificar as "queixas" e demandas espontâneas da população.

Neste artigo, tratamos de descrever e interpretar conceitos emitidos apenas pelos representantes do Conselho Municipal de Saúde. Outros resultados deverão ser tratados em outros trabalhos.

A idéia de representatividade e de construção do campo do que viria a ser chamado e considerado "saúde" perpassa todas as dimensões deste trabalho, que se deteve, no relato que se segue, nas formas de ação que giram em torno do Estado e da representação pública dos interesses dos cidadãos.

Os representantes entrevistados formulam a sua concepção sobre o campo de ação, ou seja, a saúde, a sua noção de direito, e os meios de advogá-lo. Não se trata, pois, de interpretar a noção de "direito à saúde" (Labbate, 1990) de atores direta ou indiretamente envolvidos nela, mas, partindo de representantes que legal e 
legitimamente situam-se nesse campo, interpretar as formas de promover esse direito.

\section{Discussão e resultados}

Apresentamos aqui os temas que relacionamos tomando por base as entrevistas dos representantes do Conselho Municipal de Saúde do Município de São Paulo. Na escolha dos temas descritos, priorizamos a questão das "demandas" que se relacionassem à criação de um escritório de "advocacia em saúde". Assim, de um conjunto mais amplo, expomos nesse trabalho os seguintes temas: concepção do direito à saúde; formas de reivindicação desse direito; estrutura do Estado e dos Poderes e o papel do "advogado em saúde" na cobrança do referido direito.

\section{Concepção do direito à saúde:}

A saúde como direito passa a ser discutida a partir da 'Declaration de droits de l' homme et du citoyen", mas é divulgada de maneira mais ampla no mundo após a “Declaração Universal do Direitos Humanos", aprovada a 10 de dezembro de 1948 pela Assembléia Geral das Nações Unidas. Seu artigo 25 afirma que: “Todas as pessoas têm direito a um padrão de vida adequado à saúde e bem estar próprios e de sua família, particularmente alimentação, moradia, vestimenta a assistência médica e necessários serviços sociais, edireito à segurança em caso de desemprego, doença, invalidez, viuvez, velhice ou outra falta de meios de sobrevivência em circunstâncias fora deseu controle".

Acreditando que a saúde é di reito inerente ao homem, os entrevistados assim a definiram:

“...necessidade social para atingir o bem-estar completo..." (Representante do SINDSPM).

“...é um direi to de todos... não importa se é pobre ou rico..." (Representante da Associação dos Alcoólicos Anônimos).

“...é um direi to inerente ao ser humano..." (Representante da Secretaria Municipal de Saúde - suplente).

"Acho que o direito à saúde é o direito à própria vida..." (Representante do Sindicato dos Ceramistas).

“... a partir do momento em que nasce, tem alguns direitos bási cos, como o direito à saúde... o direito começa aí..." (Representante do Conselho Municipal da Pessoa Deficiente).

Com a formação do Estado Moderno, temos a positivação do direito natural. O fim do jusnaturalismo é marcado, nesse período, com a criação das grandes codificações, especialmente a napoleônica, entrando em cena o po- sitivismo jurídico, que dá maior relevância às leis estabelecidas. Assim, entre o século XIX e $X X$, o Direito passa a assumir basicamente um papel técnico-instrumental de gestão da sociedade ao permitir, proibir, comandar, estimular e desestimular comportamentos. Esta gestão exprime-se por um Direito assinalado pela "mutabilidade e pela particularidade, positivado pelo poder estatal ou por ele coonestado, garantido pela sanção, e que tem como pressuposto a utilidade, para a sociedade, do Direito Positivo" (Comparato, 1989). Nos discursos dos entrevistados, observamos que a concepção positivista do direito é prevalentee que muitos procuraram identificar o direito com a ordem estabelecida, com as leis e as normas já instituídas:

“Ele contribui, eletem direito... já acho queé um direito... por ser um ci dadão, é contribuinte... éum brasileiro..." ( Representante do Movimento de Saúde da Zona Sul).

“Em última instância cabe ao Estado brasileiro a garantia do direi to à saúde, porque ele retém os impostos e repassa..." (Representante do Movimento de Saúde da Zona Oeste).

“Na lei está como responsabilidade do Estado..." (Representante do Movimento da Saúde da Zona Leste).

"É um direito constitucional na dimensão deum direito social..." (Representante da Faculdade de Saúde Pública).

"Sob ponto devista jurídico, a gente adquire saúde cumprindo a lei..." (Representante do Sindicato dos Hospitais).

"Todas necessi dades sociais são de responsabilidade do Estado..." (Representante do Movimento de Saúde da Zona Oeste).

Quando o Estado Liberal, de natureza individualista, que oferecia apenas a segurança do cidadão, não mais responde às necessidades do povo, consagra-se uma nova forma de atuação do Estado. Fruto do pacto social e político entre o capital-Estado-classe trabalhadora, o Estado de Bem-Estar Social altera o aparelho institucional e passa a ofertar serviços sociais (Santos, 1987). Diferentemente do que ocorre nos países de capitalismo avançado, no Brasil, não houve um pacto social e sim uma aliança conjuntural constituindo o Estado Assistencial. “O Estado Assistencial, ao contrário, apresenta-se frágil, impotente, compelindo a sociedade civil e o próprio pauperizado a cooperar na produção de serviços sociais" (Falcão, 1989). Em nossas entrevistas, a concepção da saúde como direito social aparece ligada ao Estado de Bem-Estar Social:

"É um direito do ci dadão..." (Representante da Secretaria Municipal da Saúde - suplente). 
“... é uma questão de cidadania..." (Representante do Conselho Regional de Serviço Social).

A concepção que os entrevistados têm de saúde está ligada a duas vertentes: uma assistencialista e outra relacionada às condições de vida. A visão assistencialista se materializa em uma assistência médica preventiva, curativa e de reabilitação. Espera-se sua predominância no Conselho Municipal de Saúde, em virtude da herança do Welfare State, segundo o qual o Estado tem a obrigação de ofertar serviços sociais à população:

“...tem direi to a gestação, parto tranqüilo, retaguarda médica e reabilitação ... atendimento próximo a nossas casas ... prevenção de deficiências..." (Representante do Conselho da Pessoa Deficiente).

“...tem direi to ao mínimo de atendimento bási co, prevenção feita pelas UBSs, prevenir sua doença..." (Representante do Movimento de Saúde da Zona Sul).

“...eletem direito a, no mínimo, atendimento da sua dor, na pior partedesua doença..." (Representante do Movimento de Saúde da Zona Sul).

“...deveter acesso ao serviço, que seja fácil, resol utivo, tratamento dignificante e respeito, não só para o cidadão, mas para sua família..." (Representante do Sindicato dos Hospitais).

“Ter condições de chegar à Unidade, ser atendido, ter retaguarda (exames), às especialidades ambulatoriais, internação, lei te materno ... passar no posto, ter atendimento correto, receber medicamento..." (Representante do Movimento de Saúde da Zona Centro/GAPA).

"Ter atendimento, internação, lei to..." (Representante do Movimento de Saúde da Zona Norte).

“É ter atendimento digno de saúde, começando pela UBSs, éter a unidade, o profissional de saúde, os programas... deve ser mais prevenção que cura..." (Representante do Movimento de Saúde da Zona Leste).

É no campo da fenomenologia do Direito que se encontra uma importante discussão: a efetividade da norma com o impacto e a evolução do Direito na sociedade, a correlação do fato e o direito. A efetividade é alcançada se o Direito for tratado como um sistema aberto aos fatos sociais que o abrangem e circunscrevem (Lafer, 1988).

A concepção do direito à saúde como condições de vida, "situações que fazem parte do padrão de vida adequado à saúde e bem-estar" (alimentação, moradia, vestimenta, assistência médica, serviços sociais e seguros sociais e mais trabalho e educação)..."(Labbate, 1990) constitui o que se denomina, comumente, Di- reito Social, e ultrapassa a visão da oferta dos serviços de saúde. Essa visão está incorporada no texto constitucional brasileiro a partir de 1988 e na Lei Orgânica da Saúde (Lei no 8.080, de 19/09/ 1990), que concebe a saúde como resultante de fatores determinantes e condicionantes da situação de vida; foi também expressada pelos entrevistados das seguintes formas:

“Ele tem direito de ser assistido em todas suas necessi dades... ele tem direi to de ter tudo que é bási co..." (Representante do Movimento de Saúde da Zona Sul).

"É o que está na constituição, bem-estar físi co, psíquico, social, lazer, transporte, cultura..." (Representante do Sindicato dos Servidores Públicos Municipais - SINDSPM).

“Para a população ter saúde é necessário que tenha acesso a alimentação, moradia, coisas básicas, água potável, esgotos..." (Representante do Movimento de Saúde da Zona Oeste).

“...direito a tudo: saúde, educação, saneamento básico..." (Representante do Movimento de Saúde da Zona Centro/ GAPA).

“...muito amplo, desdehabitação, lazer, educação, trabalho..." (Representante do Conselho Regional de Serviço Social).

Finalmente, outro aspecto abordado trata das ações que, politicamente, o Estado brasileiro se propôs a tutelar, entre outras a garantia universal do acesso à saúde. Ficou explicitada a insatisfação pela forma como o Estado tutela o direito que ele deve assegurar, garantir e viabilizar, e que dizem respeito às relações fundamentais de organização da cidadania:

“O papel aceita tudo... neste país não se faz leis simplizinhas para que o povo entenda, quem gosta de confusão é só quem tira proveito dela ... o que você normal mente vêéagressão ao direito..." (Representante do SINDHOSP).

“Eletem, no mínimo, di reito de atendimento na sua dor, já que o Estado não investiu na prevenção da sua doença..." (Representante do Movimento de Saúde da Zona Sul).

\section{Sobre a forma de reivindicar direitos}

Os entrevistados apontaram canais institucionalizados ou não para reivindicar o direito à saúde. Os primeiros são aqueles ligados às formas de poder instituído. Nesse caso, o Estado é compreendido como uma sociedade política que, com autoridade superior, fixa regras de convivência de seus membros (Dallari, 1983). Tradicionalmente a área de saúde coletiva é assumida socialmente como "sendo de responsabilidade do Estado e a área de saúde individual, de responsabilidade do setor privado, ainda que subsidiado pelo Estado" (Labbate, 1990). 
Os interlocutores ressaltaram a importância do Poder Executivo como instância de poder em que as demandas são mais freqüentemente solucionadas:

“O direito érei vindicado às autoridades eleitas pela população: Prefeito, Governador, o Ministro da Saúde... o Poder Executivo devepôr em prática esse direito quea população tem..." ( Representante do Movimento de Saúde da Zona Leste).

"Cabeao Executivo fazer valer estedirei to..." (Representante da Faculdade de Saúde Pública).

“Os responsáveis são o Governo do Estado, Federal e Municipal" (Representante do Sindicato dos Ceramistas).

"O direito éreivindicado às autoridades eleitas pela população" (Representante do Movimento de Saúde da Zona Leste).

Observamos que os entrevistados dão atenção diferenciada ao Poder Executivo, face à possibilidade de estabelecer canais diretos de negociação. Assim, movimentos reivindicativos, que tratam do mesmo tipo de interesses, competem entre si, principalmente, por recursos, que são sempre escassos. Chegam, inclusive, a provocar uma hierarquização entre eles, numa situação onde, teoricamente, não se admitiriam diferenciações: uns falam “...direto com o Secretário, através de audiências que nunca foram negadas" (Representante do Movimento de Saúde da Zona Centro/GAPA), enquanto a maioria dos representantes reclama da dificuldade de acesso ao Secretário: “... eaí manda para o Secretário... mas daí pra frente você não vai ficar sabendo...o retorno vai vir, mas é aquilo de sempre: não..." (Representante da Associação dos Alcóolicos Anônimos).

Os entrevistados referem uma descrença na utilização de instrumentos jurídicos de defesa:

“Com relação ao Judi ciário, a gente sempre ouve que el e tem que ser provocado... ele já tem si do provocado mas os resultados não têm sido os esperados..." (Representante do Movimento de Saúde da Zona Norte).

“O Consel ho Municipal de Saúdejá procurou o Judiciário para fazer cumprir a lei, mas infel izmente as respostas são muito lentas e a gente ainda não tem nenhum fato concreto que possa dizer que o Ministério Público atuou desta ou daquela forma em tal caso..." (Representante do SINDSPM).

A pesquisa realizada mostrou que $30 \%$ dos entrevistados consideraram o desempenho do Judiciário como ruim e péssimo, entretanto faz a ressal va que, desde maio de 94, a avaliação positiva está em alta. Pudemos perceber nas falas dos entrevistados que há uma "esperança" nessa via institucional; sem saber exatamente por que, esperam a criação de jurisprudência: “O Judiciário deve fazer com que o Executivo se submeta à lei. Ela regulamenta as relações entre os cidadãos..." ou "O jurídico vai legislar em cima de alguma lei feita pelo Legislativo. Criar jurisprudência..." (Representante do Conselho Regional de Serviço Social).

Sem dúvida, busca-se pressionar o Poder Executivo. Entretanto, sua eficácia tem sido questionada e o Poder Legislativo é citado também:

“..quando o Executivo tem um mínimo de compromisso éfácil, mas quando não tem, tem que pressionar tanto o Executivo quanto o Legislativo..." (Representante do Sindicato dos Ceramistas).

Esse Poder é visto como instância de reivindicações: “...o di rei to à saúde se reivindica aos órgãos representativos, aos legisladores, aos parlamentares, seja a nível federal, estadual ou municipal..." (Representante da Secretaria Municipal da Saúde - suplente). Os votos dos eleitores são considerados por al guns representantes como argumento para convencer políticos sobre suas reivindicações: “...a população deficiente de São Paulo, hoje, el ege um deputado, até um senador..." (Representante do Conselho Municipal da Pessoa Deficiente).

A presença de parlamentares ligados às causas sociais foi citada como forma de garantir continuidade de programa: “...na aprovação do orçamento na Câmara, através de deputado, que interveio para conseguir verba para a confecção de fol heto educativo..." (Representante do Movimento de Saúde da Zona Centro/GAPA). Deve-se considerar, entretanto, que, no caso específico, a destinação de recursos é sempre facilitada para programas de Aids, numa atitude que parece ser uma constante em nível mundial. O que parece confirmar o argumento apresentado por Cardoso (1988): “Os movimentos conseguem influir sobre a burocracia estatal, via canais políticos, para a aquisição de equipamentos, caravanas e encontros são mais eficientes quando pressionam encarregados de serviços já existentes, mas não encontram resposta quando pretendem definir novas prioridades porque o circuito decisório e de informações não estão ao seu alcance".

Na opinião dos representantes dos usuários e das entidades profissionais, as formas de pressões mais utilizadas na reivindicação do direito à saúde são aquelas realizadas pela população organizada. As manifestações públicas, a participação em audiências públicas, as reuniões plenárias, foram as formas de pressão citadas:

“Acho que todas as formas de pressão são manei ras de reivindicar...as formas de pressão é 
através da população seorganizar ereivindicar através do Conselho Municipal deSaúde eatravés dos poderes instituídos: Câmara Municipal..." (Representante do Movimento de Saúde da Zona Oeste).

“Os movimentos populares fazem pressão sobreo poder público através de manifestações de rua, plenárias amplas...direto ao Secretário, através de audi ências, nunca negadas..." (Representante do Movimento de Saúde da Zona Norte).

“... a gente conseguiu reunir na Assembléia duzentos deficientes. Em cada gabinete de deputado tinha uma cadei ra de rodas..." (Representante do Conselho Municipal da Pessoa Deficiente).

Os entrevistados ressaltaram a importância do papel dos profissionais de saúde como facilitadores na reivindicação, por serem aqueles que contribuem na "organização da luta pela saúde pública, através de orientação à população lei ga na questão saúde ..." (Representante do Sindicato dos Ceramistas) e também como participantes do processo de reivindicação como um todo: “Os técnicos têm um papel de conscientização, de informação, de estar contribuindo na discussão de todas essas informações... porque vocênem sempre entende as informações... e de estar junto nas nossas reivindicações" (Representante do Movimento de Saúde da Zona Leste).

Ora, sabe-se que os funcionários valorizam a negociação direta com os usuários dos serviços públicos como instrumento de politização das camadas populares (Cardoso, 1988) e que os órgãos terminais da administração pública são os mais sujeitos às pressões por participação dos usuários e os mais dispostos a promovê-los (Cardoso, 1988). Quando em aliança com funcionários locais, a ação popular é bem sucedida para pressionar os órgãos centrais - o que não se aplica se a pressão for sobre as próprias agências locais.

O Conselho Municipal de Saúde foi citado como via institucionalizada na reivindicação do direito: “... seria através dos poderes públicos que a gente pode rei vindicar... o Consel ho Municipal de Saúdeé o canal..." (Representante do Movimento de Saúde da Zona Oeste), enquanto os consel hos gestores foram considerados como formas não institucionalizadas de levar as demandas “....a comuni dade se organizando tem seus consel hos gestores e do lado do Estado são as autori dades públicas..." (Representante do Movimento de Saúde da Zona Oeste).

Diversos autores apontam para a dificuldade de se medir o impacto dos movimentos reivindicativos. Este campo carece de novos e constantes estudos, inclusive indicando meios e modos mais efetivos de exigir um direito e inserindo-os num contexto de tempo e espaço.

Sobre a estrutura do Estado e dos Poderes

A idéia de Estado Democrático consolidou-se como ideal supremo, de forma que nenhum sistema ou governante admite não serem democráticos. Dallari (1983) aponta três pontos fundamentais que norteiam os Estados a partir dessa idéia:

"A supremacia da vontade popular, que colocou o problema da participação popular no governo, suscitando acesas controvérsias e dando margem às mais variadas experiências, tanto no tocante à representatividade, quanto à extensão do direito de sufrágio e aos sistemas eleitorais e partidários.

A preservação da liberdade, entendida, sobretudo, como o poder de fazer tudo o que não incomodasse o próximo e como o poder de dispor de sua pessoa e de seus bens, sem qualquer interferência do Estado.

A igualdade de direitos, entendida como a proibição de distinções no gozo de direitos, sobretudo por motivos econômicos ou de discriminação entre classes sociais" (Dallari, 1983).

O Estado brasileiro, seguindo esses preceitos, organiza-se em poderes distintos e autônomos, com funções bem definidas pela Constituição, em seu Título IV: Da organização dos Poderes (arts. 44 a 135).

Percebemos no discurso dos entrevistados um reconhecimento das atribuições dos três Poderes:

“...o Legislativo estabel ecendo as normas, as regras à convivência dos ci dadãos em relação aos direitos e deveres... . O Executivo realizando as políticas que foram definidas... o Judiciário é o poder regulador, que decide os conflitos entre a legi slação e os direi tos do ci dadão, do Estado com o cidadão..." (Representante da Faculdade de Saúde Pública).

“...os interlocutores do direito à saúde no caso de São Paulo seria a Câmara Municipal, que deveria ter projeto de política de saúde..." (Representante do Movimento de Saúde da Zona Oeste).

“...só a lei ésuficiente, porquese alguém não é atendido, ele pode processar... isto aqui não é uma coisa que se faça..." (Representante da Federação das Santas Casas de Misericórdia de São Paulo).

“... Constituição, ela garantenosso direito de discutir, fiscalizar, que nos garante a participação... em termos de saúde nós temos ainda a Lei 8.080 ea Lei 8.142..." (Representante do Movimento de Saúde da Zona Sul). 
Esses conselheiros estabelecem uma forte ligação entre o Direito e o Poder, afirmando que é através do Direito que o Estado busca a legalidade do exercício do Poder: “Está previsto na Constitui ção... éo conjunto de direitos col ocados para que o cidadão se realize..." (Representante do Sindicato dos Hospitais). Segundo Lyra (1985), os inúmeros adeptos dessa concepção tendem a se fixar em um certo dogmatismo jurídico, no sentido de pensar as mudanças sociais como sendo resultantes mais de alterações no arcabouço normativo-institucional.

Entretanto, verificamos que outros reconhecem o Poder Executivo como instância mais importante, por concentrar maior poder de decisão e, sobretudo, porque sua experiência está associada à procura dos órgãos executivos para responder aos problemas ligados à violação do direito à saúde. Eles acreditam que “...a administração pública é garantidora das obrigações assumidas no pacto constitucional e que seu superior tem o dever de prestar contas da sua conduta em relação àquelas obrigações ao povo" (Dallari, 1995).

O Poder Judiciário é a instância acionada para dirimir os conflitos. Apesar disso, o Legislativo, mesmo vinculado, no momento, a "estórias" de malversação do erário público, demonstrando a fragilidade e descrédito nos mecanismos de representação política, é mencionado como a instância de poder que deveria elaborar leis que resolvessem os litígios. As especificidades do Poder Judiciário o tornam, aparentemente, uma instância ineficaz e distante dos anseios dos entrevistados, porque exige iniciativa do cidadão, ou entidade civil organizada. Com efeito, "trata-se de um poder distinto dos outros, pois só atua mediante provocação. Assim, se o Executivo e o Legislativo podem dar início espontaneamente a reformas, o mesmo não se dá com o Judiciário" (Lopes, 1994).

“O Executivo éque devegarantir o direito...é obvio que ao Judi ciário, quando não há aplicação, cabe agir, idem para resolver os conflitos... . O Estado como um todo é que importa para garantir o di reito..." (Representante da Secretaria Municipal de Saúde - suplente).

“A verdade éuma só, se não se tem vontade política do Poder Executivo para fazer alguma coisa, não acontece nada..." (Representante do Sindicato dos Hospitais).

Aparece também, contrapondo essa afirmação, uma certa confusão entre o que deveria ser e o que na realidade acontece:

“Só a lei, é suficiente, porque se alguém não for atendido, ele pode processar, isto aqui não é coisa que se faça... eu acho que quem não for atendido pode abrir um processo... é que as coi- sas são difíceis no Brasi l... então nós temos que considerar que tem que ser cumprida a lei, se não dá, então tem que ser mudada a Constituição..." (Representante da Federação das Santas Casas de Misericórdia de São Paulo).

O papel do advogado na reivindicação do direito à saúde

As primeiras experiências de "advocacia em saúde" ocorreram quando um grupo de pediatras resolveu reivindicar a garantia dos direitos de crianças (AAP, 1977). No início, essa atuação se restringia a profissionais de saúde ligados às instituições, mas aos poucos entidades não governamentais foram desenvolvendo experiências no monitoramento de programas governamentais destinados às crianças, atuando assim como seus “advogados" (Knitzer, 1976).

Representantes do governo e prestadores de serviços tiveram dificuldade em responder a este questionamento. Houve respostas variadas quanto ao papel do "advogado", seguramente porque a singularidade do termo empregado pelos entrevistadores não era familiar aos entrevistados. No entanto, funções como informar, orientar, participar da reivindicação foram citadas pelos entrevistados como papel do "advogado". É importante, todavia, notar que a pessoa do "advogado" apareceu de forma contraditória. Para um representante dos prestadores de serviços, o "advogado" deve ser pessoa integrante das instituições públicas que defenda os direitos: “...não se criou o PROCON, vocêtem que ter... apesar de que teoricamente este PROCON abrangendo tudo, trata dedireito do consumidor, mas aquilo não é um direito substantivo, é um direito objetivo da vida, você tem queter al guma coisa que seja específica para a área da saúde, que é muito mais complexo..." (Representante do Sindicato dos Hospitais). Porém, alguns tomaram para si o papel do "advogado": “É um papel de muita responsabilidade, você acaba fazendo pesquisa, acaba discutindo com a pessoa lesada ou discutindo um projeto lesado, você acaba tendo uma responsabilidade muito grande em relação a isso, né? Você tem que acompanhar, você acaba fazendo o papel do diabo porqueaí vocêfica: será queéisso, será queéaquilo, porque vocênão conhece di reito a lei, você sabe de al guns di reitos mas não são todos que você sabe. Você sabe ondeéo direito mesmo, então vocêpode ir... então é de muita responsabilidade, não é muito fácil delidar com isso, não... vocêleva atéo local onde tem que levar a reivindicação e estar lá exigindo..." (Representante do Movimento de Saúde da Zona Leste). 
Outro, apesar de ser representante, delega ao CMS/SP a figura impessoal do "advogado": “... o Consel ho deveria ser o advogado, influir nas diretrizes. ele deve ser reformulado e funcionar como tal..." (Representante da Secretaria Municipal de Saúde). Também foi destinado ao "advogado em saúde" a realização de lobby, que, segundo Lodi (1982), é "um instrumento de ação junto ao poder público e representa um ato de influenciar sobre a decisão". Os entrevistados referiram esse papel como: “... fazer um trabalho com muita calma e consciência mas sendo persistente, constante, indo ao lugar correto, insistir com grupos para passar mensagem..." (Representante da Federação das Santas Casas de Misericórdia do Estado de São Paulo).

\section{Agradecimentos}

Esta investigação foi realizada com a colaboração dos alunos da Disciplina de Pós-Graduação “Advocacia em Saúde Pública".

\section{Referências}

AAP (American Academy of Pediatrics), 1977. Handbook Child Advocacy. New York. (mimeo.)

ADORNO, R. C. F., 1992a. Movimento social e participação na esfera pública. Saúde e Sociedade, 1:111-124.

ADORNO. R. A. F., 1992b. Sociologia de ação e atores na saúde. In: Pesquisa Social em Saúde (A. W. P. Spinola, E. N. C. Sá, M. F. Westphal, R. C. F. Adorno \& F. Zioni, coords.), pp.125-128. São Paulo: Editora Cortez.

ASSEM BLÉIA GERAL DAS NAÇÕES UNIDAS, 1948. Declaração Universal do Direitos Humanos. Genebra: ONU.

BOBBIO, N.; MATTEUCCI, N.; GI AFRANCO, P., 1992. Dicionário de Política. Vol. 1, Brasília: Ed. Universidade de Brasília.

CARDOSO, R.,1988. Os movimentos populares no contexto da consolidação democrática. Revista dos Tribunais, 7:368-382.

COM PARATO, F. K., 1989. Para Viver a Democracia. São Paulo: Editora Brasiliense.

CONSTITUIÇÃO DA REPÚBLICA FEDERATIVA DO BRASIL, 1988. Promulgada em 5 de outubro de 1988. Brasília.

DALLARI, D. A., 1983. Elementos da Teoria Geral do Estado. São Paulo: Editora Saraiva.

DALLARI, S. G., 1995. Os Estados Brasilei ros e o Direito à Saúde. São Paulo: Hucitec.

FALCÃO, M. C., 1989. A seguridade da travessia do Estado assistencial brasileiro. In: Os Direitos dos (De sassistidos) Sociais (A. Spozzati, org.), p.119, São Paulo: Editora Cortez.

JACOBI, P., 1989. Movimentos Sociais e Políticas Públicas. São Paulo: Editora Cortez.

\section{Conclusão}

O trabalho demonstrou ser positivo o uso de metodologias das ciências sociais que aliassem a observação de campo às entrevistas. Possibilitou descrever o discurso dos "conselheiros", e, a partir desses, interpretar questões pertinentes na linha da "advocacia em saúde", que representa uma nova instância de apoio e assessoria aos "movimentos sociais" que buscam a melhoria do atendimento e da saúde coletiva da população brasileira, tendo como base a participação local, em um município complexo, desmesurado e desigual como o de São Paulo.

O discurso mais recorrente com relação ao direito à saúde se refere a algo inerente ao ser humano, que numa visão jusnaturalista sobrepõe a existência do Estado ou das leis, mas que cabe ao primeiro garanti-lo. Para os entrevistados, as leis são apontadas como um importante instrumento, que deve ser utilizado para fazer valer o direito.

Esse conteúdo será desenvolvido em treinamentos para membros de Conselhos Municipais de Saúde.

KNITZER, J. E., 1976. Child advocacy: a perspective. American Journal of Orthopsychiatry, 46:200-216.

LABBATE, S., 1990. O Direito à Saúde: da Reivindicação à Realização. Tese de Doutorado, São PauIo: Faculdade de Filosofia, Letras e Ciências Humanas, Universidade de São Paulo.

LAFER, C., 1988. A Reconstrução dos Direitos Humanos: um Diálogo com o Pensamento de Hannah Arendt. São Paulo: Companhia das Letras.

LODI, J. B., 1982. Lobby e Holding: As Bases do Poder. São Paulo: Pioneira.

LOPES, J. R. L., 1994. Direito subjetivo e os direitos sociais: o dilema do judiciário no Estado Social de Direito. In: Direitos Humanos, Direitos Sociais e Justiça (J. E. Faria, org.), p.134, São Paulo: Ed. Malheiros.

LYRA, F. R., 1985. O QueéDireito. São Paulo: Editora Brasiliense.

SADER, E., 1988. Quando Novos Personagens Entram em Cena: Experiências, Falas e Lutas dos TrabaIhadores da GrandeSão Paulo, 1970-80. Rio de Janeiro: Editora Paz e Terra.

SANTOS, B. S., 1987. O Estado, a sociedade e as políticas de saúde. Revista Crítica de Ciências Sociais, 23:13-73.

TOURAINE, A., 1984. Le Retour del' Acteur. Paris: Fayard.

TOURAINE, A., 1989. A Palavra eSangue: Política eSociedadena América Latina. Campinas: Ed. Unicamp.

VALLA, V. \& SIQUEIRA, S. A. V., 1989. O centro municipal de saúde e a participação popular. In: Demandas Populares, Políticas Públicas e Saúde (N. R. Costa, org.), pp.45-65, Petrópolis: Vozes. 